\title{
A FONDO
}

\section{Coronavirus}

Pedro Rubio, Ana Carvajal. Enfermedades Infecciosas. Dpto. de Sanidad Animal. Facultad de Veterinaria. Universidad de León

\section{Resumen}

Las enfermedades causadas por coronavirus son conocidas y han sido estudiadas en veterinaria muchos años antes que en medicina humana por su importancia y por sus efectos en distintas especies de aves y de mamíferos. La primera vacuna contra una enfermedad por coronavirus en animales, la bronquitis infecciosa aviar, se desarrolló en 1950 mientras que el primer coronavirus humano se describió en 1965.

En el presente trabajo se hace una revisión histórica de los aspectos que pueden ser más interesantes de las enfermedades causadas por coronavirus, aportando algunas experiencias propias con enfermedades causadas por coronavirus en el cerdo, algunas de ellas emergentes e ilustrativas de lo que son estas enfermedades.

Se resaltan las características epidemiológicas de las zoonosis causadas por coronavirus, su origen y el carácter preocupantemente emergente de las mismas en medicina humana; es por esto que el conocimiento de los antecedentes de la pandemia actual causada por SARS-CoV-2 resultan muy elocuentes a la hora de interpretar la actual emergencia sanitaria, que aunque sorpresiva no resulta un hecho inesperado.

\section{Introducción}

En 1968 se publicó una nota en la revista Nature: "Un nuevo grupo de virus con el nombre de coronavirus ha sido reconocido por un grupo informal de virólogos...". Según los firmantes, estos virus de morfología redondeada y con proyecciones externas, al ser observados al microscopio electrónico se parecían a la corona solar y propusieron denominarlos coronavirus. En 1975 el comité internacional para la taxonomía de virus (International Committee on Taxonomy of Viruses; ICTV) los clasificó en la nueva familia Coronaviridae.

Los virus de esta familia tienen una envoltura y un genoma de ARN monocatenario de polaridad positiva de 27 a 32 kilobases, el de mayor tamaño de todos los virus ARN. El ARN vírico sirve de ARN mensajero (ARNm) para sintetizar las proteínas del virus en las células hospedadoras, entre las que se encuentra una ARN polimerasa dependiente de ARN (ARNpARNd), la cual será utilizada para generar otros transcritos (subgenomas) y finalmente para replicar el genoma completo. 
El ICTV clasifica actualmente a los coronavirus que nos interesan en la subfamilia Coronavirinae, que a su vez se divide en los géneros Alphacoronavirus, Betacoronavirus, Gammacoronavirus y el aún no reconocido Deltacoronavirus. El más diverso es el Betacoronavirus, que engloba los subgéneros Embecovirus, Hibecovirus, Merbecovirus, Novecovirus y Sarbecovirus y muchos otros virus aún no clasificados, con un porcentaje alto de ellos detectados en murciélagos.

Los análisis evolutivos han llevado a la conclusión de que los murciélagos y los roedores son el origen principal de Alfa- y Betacoronavirus, mientras que las aves constituyen el reservorio principal de Gamma- y Deltacoronavirus, indicando que los coronavirus han cruzado las barreras de especie, pasando de un animal a otro a lo largo de miles de años (Cui et al., 2019).

Los murciélagos son reservorios de multitud de virus porque las adaptaciones que estos mamíferos han adquirido para soportar las consecuencias del elevadísimo gasto metabólico que necesitan para el vueloy para hacer frente a las moléculas oxidantes perjudiciales (especies reactivas) les han permitido adaptar eficazmente su sistema inmune para soportar infecciones por muchos virus sin padecer enfermedades (Subudhi et al., 2019).

Hay una cantidad enorme de especies de coronavirus, la mayor parte Betacoronavirus. Un estudio reciente de EcoHealth Alliance (https:// www.ecohealthalliance.org/), del Instituto de Virología de Wuhan y de otras instituciones, describe la detección de 630 nuevas secuencias de coronavirus en murciélagos. Está aún arrancando el Global Virome Project (http:// www.globalviromeproject.org/) cuyo objetivo es encontrar virus zoonóticos y prevenir pandemias futuras. Se espera que aporte miles de secuencias de nuevos coronavirus.

\section{Primeros coronavirus animales}

Los coronavirus eran conocidos mucho antes en el mundo veterinario que en medicina humana. En 1931 dos veterinarios describieron una "bronquitis infecciosa" que afectaba a los pollos y en 1933 se comprobó que estaba causada por un agente "filtrable" (Fabricant, 1998). En 1936 se demostró que estaba causada por un virus, el virus de la bronquitis infecciosa (en inglés IBV) y en 1937 se consiguió cultivarlo en embriones de pollo, siendo esta la primera descripción de una enfermedad causada por coronavirus. Los veterinarios trabajaron con gran eficacia con este primer coronavirus cuando las técnicas de laboratorio no se parecían ni remotamente a las actuales.

El virus de IBV es del género Gammacoronavirus, en el que está también 
clasificado otro virus aislado de las ballenas beluga (Delphinapterus leucas).

En 1940, un veterinario de la Universidad de Massachusetts demostró que era posible proteger a las gallinas exponiéndolas al coronavirus IBV atenuado por pases sucesivos en embriones de pollo. Poco después, al comienzo de los años 50 se desarrolló la primera vacuna con la cepa que había desarrollado, la "Van Roekel M41" (cepa Massachusetts), que fue la primera vacuna frente a una enfermedad por coronavirus (Jordan, 2017).

En 1963, también antes de conocerse el primer coronavirus humano, Jean Holtzworth, del Angell Memorial Animal Hospital, en Boston (EE. UU.), describió una enfermedad en los gatos a la que llamó "peritonitis crónica fibrosa". En 1966 dos veterinarios de la Universidad de Ohio reprodujeron la enfermedad experimentalmente, la denominaron con su nombre actual, peritonitis infecciosa felina y propusieron que estaba causada "por un agente pequeño como un micoplasma o un virus", aunque no consiguieron demostrarlo. En 1970 se indicó el parecido de este virus con los coronavirus conocidos y en 1976 se consiguió cultivarlo por primera vez (Pedersen et al., 1981). También hay una vacuna comercial contra esta enfermedad, que en una de sus formas clínicas es mortal para el gato.

\section{Coronavirus del cerdo}

Nuestro grupo de investigación, especializado en infecciones digestivas del cerdo, ha trabajado sobre dos enfermedades causadas por coronavirus: la gastroenteritis transmisible (GET) y la diarrea epidémica porcina (DEP); fruto de la investigación sobre esos virus se han realizado cuatro tesis doctorales y una más está en proceso de elaboración.

Ambas enfermedades tienen una historia ilustrativa. La GET se describió en 1946 y en 1954 se descubrió que estaba causada por un virus, aislado en 1968 e identificado en 1970 como un representante de coronavirus. La GET fue una enfermedad importante durante décadas, sobre todo en América, pero también en Europa (Laude et al., 1990).

Frecuentemente se habla de las mutaciones como algo que confiere nuevas capacidades a los virus para ser más virulentos, pero en el caso del virus de la GET sucedió lo contrario. El Prof. Pensaert, con el que hemos colaborado, fue Catedrático de Virología de la Facultad de Veterinaria de Gante (Bélgica). En 1984 detectó un aumento súbito del porcentaje de cerdos con anticuerpos frente al virus causante de la GET sin que hubiera aumentado la incidencia de la enfermedad y en 1986 descubrió que una pequeña mutación en el genoma del virus digestivo de la GET había generado un nuevo virus, al que llamó coronavirus 
respiratorio porcino (CVRP). La mutación afectó a la proteína $\mathrm{S}$ de las espículas (spike) que conforman la corona, e hizo que el nuevo virus se comportara de una forma totalmente diferente; este virus tiene tropismo por el aparato respiratorio y causa una infección inaparente o muy leve. Al ser un virus respiratorio se difundió rápidamente en la población porcina europea y la inmunizó contra el virus digestivo porque ambos son muy similares antigénicamente (Laude et al., 1993).

La mutación fue una gran ventaja evolutiva para el virus. El CVRP se transmite por el aire y no provoca cuadro clínico, por lo que se difunde con mucha facilidad por el aire o por cerdos portadores asintomáticos y alcanzó pronto a la mayoría de las granjas. España entró en la UE en 1986 y hasta entonces no importábamos cerdos de otros países. Cuando se abrieron las fronteras, el CVRP llegó de inmediato con cerdos importados y se difundió rápidamente. En este caso, la mutación evolutivamente ventajosa para el virus fue también ventajosa para los hospedadores, los cerdos. $\mathrm{Al}$ infectarse con el virus respiratorio quedaban inmunizados frente al virus digestivo, dando lugar a un auténtico fenómeno de "vacunación natural" dela población.

Actualmente continuamos trabajando con el virus de la DEP, que tiene una historia distinta. La enfermedad se describió en 1976 y de nuevo el grupo del Prof. Pensaert aisló un virus desconocido con morfología de coronavirus en 1977. La DEP es una enfermedad similar a la GET aunque más leve. Está presente en cerdos de muchos países europeos y en España hubo numerosos brotes en la década de 1990 y sigue habiendo casos actualmente (Carvajal et al., 2015).

El virus de la DEP llegó a Asia, aunque no se pudo determinar su origen y durante años en China y Corea del Sur hubo brotes similares a los de Europa, pero en el invierno de 2009-2010 empezó un brote muy grave en el sur de China, la zona más productora del mayor productor mundial de cerdos. La zona tenía un censo de más de 400 millones de animales, y decimos tenía porque la llegada reciente de la peste porcina africana, una de las enfermedades más graves del cerdo, ha hecho que su censo sea actualmente de unos 150 millones de cerdos menos.

Esta nueva forma de la DEP afectó a cerdos de todas las edades, causando una diarrea grave con mortalidades en lechones de hasta el $90 \%$ y rápidamente se extendió por todo el país causando la muerte a muchos millones de lechones.

Se comprobó que el virus original de la DEP también había sufrido una mutación en la proteína $S$ de las espículas, pero en este caso se había originado un virus mucho más virulento que el original, al contrario de lo que había sucedido con el virus de GET. 
En el continente americano no había habido nunca DEP, pero en 2013 llegó a EE. UU. la cepa china virulenta del virus que se extendió rápidamente y pasó después a otros países americanos. Se ha calculado que, solo en EE. UU., la DEP mató inicialmente a más de 8 millones de lechones aparte de otras pérdidas en reproductores y cerdos de cebo. Una auténtica catástrofe. Se sabe que el virus procedía de China porque su secuencia era casi idéntica a la cepa "CHN/AH2012", esta última muy extendida en China y muy virulenta. Actualmente no se sabe cómo llegó este virus a EE. UU., pero todo apunta a que pudo llegar en materias primas para la elaboración de piensos, probablemente a través de la contaminación de los contenedores empleados en el transporte (Huang et al., 2013).

La difusión de esta variante muy virulenta de la DEP causó alarma en Europa, temiendo las consecuencias que pudiera tener en la industria porcina. En España, en 2014 el Ministerio de Agricultura financió un proyecto a nuestro laboratorio, realizando de esta forma el primer estudio de la situación epidemiológica y del impacto de la enfermedad por DEP. No era ni mucho menos tan grave como lo que estaba pasando en EE. UU., pero aun así en los brotes de ese año la mortalidad media de los lechones lactantes fue elevada.

En una segunda fase del proyecto se estudiaron los virus que estaban circulando en España, secuenciando el genoma completo de algunos de ellos y concretamente en el gen $\mathrm{S}$ de las espículas de 24 aislados, incluyendo muestras de los años 90 que aún conservábamos. Comprobamos que los virus que circulaban en España en 2014 y también los de los años 90 eran similares a variantes mucho menos virulentas del virus (denominadas INDEL) que presentaban algunos cambios en el gen para la proteína $S$. Esta menor virulencia explicaba que el cuadro clínico fuera mucho más leve que el descrito en EE. UU., afortunadamente para las empresas productoras de porcino españolas y europeas (de Nova et al., 2020).

\section{Emergencia de nuevos coronavirus en el cerdo}

Los coronavirus del cerdo están dando en tiempos recientes sorpresas llamativas. En 2009 en Italia hubo problemas en granjas con diarrea acuosa en cerdas reproductoras y mortalidad en lechones, aunque menor que la habitual en brotes de DEP o de GET. Los resultados de laboratorio aplicando técnicas convencionales eran poco concluyentes y, tras los análisis genómicos, se describió un nuevo representante que se denominó coronavirus entérico porcino (Swine Enteric coronavirus, SeCoV) (Boniotti et al., 2016). Este se había originado por recombinación de los dos virus digestivos "clásicos", el causante de DEP y el de GET. En algún momento y en algún lugar, algún cerdo fue infectado a la vez por 
los dos virus citados que recombinaron sus genes y originaron un virus nuevo, demostrando una vez más la elevada capacidad natural de los coronavirus para la recombinación. Después se describió la presencia de este virus en otros países europeos.

En nuestro grupo hemos estudiado muestras actuales y las que conservábamos desde 1993 y se ha comprobado que este virus recombinante estaba ya circulando en España al menos desde ese año (de Nova et al., 2020). El virus había pasado desapercibido porque en los años 90 no estaban disponibles las técnicas de secuenciación actuales. Las técnicas que se usaban entonces daban reacciones cruzadas con el virus causante de DEP y las muestras se consideraban positivas para este virus. Por tanto, el virus recombinante pudo haberse originado hace más de 25 años.

$\mathrm{El}$ coronavirus $\mathrm{SeCoV}$ es considerado nuevo porque se ha identificado y diferenciado recientemente, pero realmente es bastante más "viejo" de lo que se pensaba. En España estaba desde la década de 1990y, dado que en España no hubo prácticamente casos de GET, también es posible que se originara por recombinación del virus de la DEP y del CVRP, el coronavirus respiratorio porcino derivado del virus digestivo de la GET. Se ha demostrado experimentalmente que una cepa del virus de la DEP de alta virulencia puede infectar células de la cavidad nasal y llegar después al intestino, por lo que la posibilidad de recombinación del virus de la DEP con el CVRP no es descabellada.

Las sorpresas con los coronavirus del cerdo no habían acabado; en 2009 se encontraron en China coronavirus nuevos y diferentes en aves, ahora clasificados en el género Deltacoronavirus (DCoV), creado ex profeso para ellos. Poco después, en 2012, el mismo grupo de investigación estudió muestras de diversos mamíferos (leopardos asiáticos, gatos, perros, cerdos, roedores, monos y humanos) y de distintas especies de aves. Solo encontraron Deltacoronavirus en aves silvestres y en cerdos, con un $10 \%$ de las muestras de cerdos positivas. Estos autores describieron 7 nuevos coronavirus, entre ellos uno presente en cerdos, al que llamaron PDCoV HKU15 (Wang et al., 2015). En 2014, el Departamento de diagnóstico veterinario de la Universidad de Iowa (EE. UU.), recibió muestras de una granja con un brote agudo de diarrea que afectaba a cerdas y lechones. En estas muestras se identificó un Deltacoronavirus que se denominó USA7IA/2014/8734, diferente del virus HKU15 de procedencia china, pero con una homología del $99 \%$, lo que indicaba una potencial nueva importación de este otro coronavirus desde China (Li et al., 2014).

Poco después el laboratorio de diagnóstico veterinario de la Universidad de Minnesota (EE. UU.) encontró en muestras de cerdos con diarrea otro repre- 
sentante de Deltacoronavirus, el SDCV/USA/Illinois121/2014, con la misma homología del $99 \%$ con las cepas virales de origen chino (Marthaler et al., 2014). Después se identificaron virus similares en otros estados, y un estudio retrospectivo demostró que el virus llevaba presente en EE. UU. al menos desde agosto de 2013. También se identificaron Deltacoronavirus con una gran homología en su genoma en cerdos en Canadá, Corea del Sur, China, Tailandia, Laos y Vietnam.

El PDCoV causa en las granjas un cuadro de diarrea acuosa en cerdos de todas las edades con mortalidad alta en lechones, considerándose un virus emergente aún poco conocido y estudiado.

En 2016 aparece un nuevo coronavirus causante de diarrea en cerdos, de nuevo con procedencia China; en octubre de ese año hubo un primer caso de diarrea grave en Guandong, cerca de donde apareció en 2002 el primer caso humano de SARS-CoV. El cuadro incluía vómitos y diarrea aguda en lechones lactantes con una mortalidad de hasta el $90 \%$ cuando tenían menos de 5 días de vida. Las cerdas madre padecían solamente una diarrea leve y se recuperaban en 23 días.

Cuando se hizo un análisis metagenómico de muestras de intestino de los lechones, se detectó un nuevo coronavirus al que se denominó SADS-CoV (Swine Acute Diarrea Syndrome Coronavirus) que era muy similar al Betacoronavirus HKU2 aislado de murciélagos de herradura chinos del género Rhinolophus, de los que ya se conocía que eran el reservorio del virus humano del SARS (Zhou et al., 2018). Después se identificaron virus muy relacionados en casi el $10 \%$ de muestras de heces de murciélago recogidas de zonas próximas, sobre todo en los murciélagos del género Rhinolophus.

¿Qué enseñanzas podemos sacar a partir del conocimiento relativo a los representantes de coronavirus del cerdo? La aparición del mutante respiratorio del virus de GET señala su capacidad de mutación. Este virus se difundió además con gran rapidez por toda la cabaña porcina de Europa, lo que resalta la facilidad de difusión de los coronavirus respiratorios, como el de la pandemia actual.

Ha habido discusiones bizantinas sobre si el SARS-CoV-2 se transmite o no por aerosoles y algunas autoridades han dicho repetidamente que "no había evidencias científicas". Conociendo de forma genérica la epidemiología de los coronavirus, en principio, hay que dar por supuesto que se trasmiten por aerosoles y, en todo caso, habría que buscar evidencias científicas de lo contrario.

Por otra parte, los coronavirus del cerdo han puesto de manifiesto que también hay mutaciones que pueden dar lugar a nuevos virus o nuevas cepas virales más virulentos/as, como las cepas asiáticas del virus de la DEP. Además, 
también hay recombinaciones, como el caso del coronavirus entérico porcino originado por recombinación del virus de la GET y el de la DEP.

Por último, los coronavirus del cerdo indican que emergen nuevos coronavirus que afectan al cerdo, pero que proceden de otras especies. Los nuevos Deltacoronavirus proceden mayoritariamente de aves mientras que los Betacoronavirus y Alphacoronavirus tienen su origen en murciélagos.

Ya hemos indicado que los murciélagos son el reservorio de una enorme cantidad de virus, entre ellos muchos coronavirus. Hay una magnífica base de datos de virus asociados con murciélagos (Data Base of Bat-Associated Viruses) que registra 2.286 virus asociados a los murciélagos frugívoros, (Megachiroptera), 8.527 asociados a las distintas familias de murciélagos de pequeño tamaño (Microchiroptera), y otros 601 asociados a quirópteros sin clasificar, con un total de 11.414 representantes virales; de ellos, 4.027 (35\%) pertenecen al grupo de coronavirus, por lo que el porcentaje de coronavirus en murciélagos es muy considerable.

Las alteraciones medioambientales y la invasión de ecosistemas silvestres favorecen el contacto de los murciélagos con animales domésticos, como el cerdo, y con el hombre y facilitan su transmisión interespecífica.

\section{Los coronavirus humanos}

Hasta ahora, hay descritos siete coronavirus humanos: dos Alphacoronavirus que causan resfriados, el 229E y el NL63, y cinco representantes de $B e$ tacoronavirus, siendo dos de ellos los virus de resfriados OC43 y HKU1. Los otros tres representantes son coronavirus muy patógenos recientemente descritos y que han originado epidemias graves: SARS-CoV, virus que causa el síndrome respiratorio agudo grave (Severe Acute Respiratory Syndrome Coronavirus), el MERS-CoV que causa el síndrome respiratorio de Oriente Medio (Medium East Respiratory Syndrome) y el SARS-CoV-2, el virus de la pandemia actual que causa un Síndrome Respiratorio Agudo Grave-2, conocida como COVID-19 (coronavirus disease-19) (Petrosillo et al., 2020).

En 1965 se descubrió el primer coronavirus humano, el 229E, y poco después el OC43, siendo en ambos casos causantes de resfriados, por lo que al tratarse de enfermedades leves la comunidad médica no se molestó en investigar los coronavirus.

Ahí quedó la cosa en medicina humana hasta que apareció en China el virus del síndrome respiratorio agudo grave (SARS-CoV) en noviembre de 2002 (Knobler et al., 2004; Hilgenfeld y Peiris, 2013). En 2003 un portador asintomático lo llevó a Hong Kong y desde allí se extendió causando una epidemia que 
afectó a 8.096 personas en 29 países, con 774 muertos, una letalidad próxima al $10 \%$. Este virus tenía un número básico de reproducción $\left(\mathrm{R}_{\mathrm{o}}\right)$ bajo $\mathrm{y}$, afortunadamente se controló la infección ya que los pacientes mostraban sintomatología en el momento en el que la transmisibilidad estaba en su apogeo, por lo que su control resultaba bastante efectivo. Desde 2004 no se han descrito más casos, pero la elevada mortalidad del virus conocido ahora como SARS-CoV-1, cambió por completo la percepción de los coronavirus en medicina humana.

Cuando emergió el SARS no se sabía aún que los murciélagos pudieran ser reservorios de coronavirus, pero ya empezaron los indicios a partir de dos representantes de la familia Paramyxoviridae; en 1994 emergió en Australia el virus Hendra, afectando y causando muertes en caballos y humanos, aislándose poco después en murciélagos frugívoros. Algo más tarde, en 1999, emergió en Malasia el virus Nipah, que causó una enfermedad relativamente leve en cerdos, pero que causó la muerte a 105 personas en un primer brote; este virus fue también aislado inmediatamente de murciélagos (Wang et al., 2015).

En 2003 se aisló el virus del SARS en civetas de las palmeras (Paguma larvata) en mercados chinos de animales vivos, apuntando a que la enfermedad era una zoonosis que provenía de animales (Wang et al., 2006; Ye et al., 2020). Poco después se encontró un virus muy similar al humano en heces de murciélagos de herradura chinos (Rhinolophus sinicus). El origen del virus eran los murciélagos y las civetas fueron las hospedadoras que lo amplificaron y lo acercaron al hombre.

En 2003 se descubrió otro coronavirus del resfriado en los Países Bajos, el HCoV-NL63, también del género Alphacoronavirus, y en 2005 otro nuevo en Hong Kong, el HCoV-HKU1, del género Betacoronavirus. Los cuatro virus del resfriado son muy comunes, todos hemos tenido un resfriado y estamos más o menos inmunizados contra alguno o varios de ellos.

En 2012 emergió otro coronavirus zoonótico aún más virulento, el del síndrome respiratorio de Oriente Medio (MERS). Se aisló de un paciente que murió en Jeddah (Arabia Saudí) y se clasificó como un Betacoronavirus similar al SARS-CoV, pero genéticamente más próximo a dos coronavirus de murciélagos, el de Pipistrellus $\mathrm{HKU}_{5}$ (BtCoV-HKU5) y el de Tylonycteris (BtCoV-HKU4) (Singh, 2014; Gao et al., 2016; Scheld et al., 2016).

El 14 de septiembre de 2012 la Agencia de Protección de la Salud del Reino Unido recibió la notificación de un caso de enfermedad respiratoria muy grave en un paciente ingresado en Londres en una UCI que había sido trasladado desde Qatar y que había viajado antes a Arabia Saudí. Padeció una enfermedad respiratoria leve y no diagnosticada en agosto mientras visitaba Arabia y el 3 de septiem- 
bre empeoró y fue ingresado en un hospital de Qatar, donde a pesar de diversos tratamientos siguió empeorando hasta que decidieron trasladarlo a Londres. El virus del MERS había viajado rápidamente ya al Reino Unido.

En septiembre de 2013 había ya 108 casos confirmados de MERS, 50 de ellos mortales. Se habían descrito infecciones locales en Jordania, Arabia Saudí, Qatar y Emiratos Árabes Unidos y casos secundarios, a veces con transmisión local en el Reino Unido, Francia, Alemania, Italia y Túnez.

A finales de enero de 2020, la OMS registraba 2.519 casos de MERS en 27 países con 866 muertes (34,3\%), una enfermedad muy grave. La mayor parte de los casos se han diagnosticado en Arabia Saudí: 2.121 casos con 788 muertes.

Los estudios epidemiológicos determinaron que la fuente principal de contagio del virus de MERS son los camellos y que la transmisión es respiratoria (Ohd et al., 2016). Hay también contagio entre personas, principalmente en ambientes hospitalarios.

Se determinó también que el origen inicial del virus son los murciélagos que contaminan con sus heces u orina el agua o el pienso de los camellos. Cerca de La Meca se aisló el virus en murciélagos de tumba egipcios (Taphozous perforatus) capturados cerca del domicilio de un enfermo poco después del primer caso humano (Shehata et al., 2016).

Después se hizo un estudio que abarcó, entre otras, muestras de heces de cuatro especies de murciélagos Pipistrellus capturados en cuatro países europeos (Annan et al., 2013). Se detectaron Betacoronavirus en 40 (14,7\%) de los 272 Pipistrellus de distintas especies capturados en Holanda, Ucrania y Rumanía. La carga vírica que se detectó en las heces fue en algunas ocasiones muy elevada. El genoma de uno de los virus de murciélagos europeos, el VM314, solo se diferenciaba en un 1,8\% del MERS-CoV.

Por tanto, murciélagos muy comunes en Europa y muy próximos al hombre están infectados con coronavirus similares al virus del MERS, algo que debe ser tenido en consideración en la vigilancia de las zoonosis por coronavirus.

Es interesante resaltar el foco de MERS que hubo en Corea del Sur, y cuya experiencia sirvió a este país para enfrentarse a la pandemia actual (Cho et al., 2016). El 20 de mayo de 2015 se confirmó un primer caso en un coreano que tenía negocios en la Península Arábica y que había viajado allí. Volvió a Corea del Sur el 4 de mayo sin síntomas, el 11 de mayo empezó con fiebre y se le diagnosticó de MERS el 20 de mayo. De inmediato, todos los que habían tenido contacto con él desde que empezó con fiebre, 742 personas, fueron sometidos a vigilancia. El día 20 de mayo ya habían sido diagnosticados 28 infectados: personal sanitario, otros pacientes y 13 personas más entre celadores, visitantes y personal de segu- 
ridad de los hospitales.

Tres de los infectados por el paciente inicial fueron lo que epidemiológicamente se conoce como "superdifusores", porque cada uno de ellos infectó a otras 5 personas. El virus alcanzó a numeroso personal de los hospitales en los que había estado el paciente, pero también se diseminó mucho, hasta afectar a otros 17 hospitales debido al movimiento de pacientes y de personal sanitario entre ellos.

A finales de julio había 186 casos confirmados, la mayoría de ellos contagiados en hospitales, con 38 muertes (19,4 \%) y aún quedaban 12 pacientes en tratamiento. Se sometieron a cuarentena más de 16.600 personas y se cerraron temporalmente cientos de colegios. El brote tuvo repercusiones económicas importantes, porque hubo descensos notables del comercio y se cancelaron más de 100.000 viajes turísticos y, para paliarlas, el Banco Central de Corea del Sur rebajó los tipos de interés en 0,25 puntos.

De nuevo una sola persona infectada había trasportado un coronavirus zoonótico que se transmite por vía respiratoria a miles de kilómetros. ¿̇es suena esto?

Las conclusiones que sacaron las autoridades de Corea fueron: a) es necesario un mayor conocimiento epidemiológico sobre la forma de transmisión del virus; b) hay que mejorar las técnicas de rastreo epidemiológico utilizando cámaras de circuitos cerrados de televisión y sistemas de GPS; c) hay que identificar muy rápidamente a las personas en contacto con un caso; d) hay que aprender de la experiencia de cuarentena de los contactos; d) se deben reconsiderar los sistemas de detección de brotes de enfermedades contagiosas tanto a nivel del gobierno central, como de los gobiernos locales y del público; e) se debe revisar la forma de gestionar las enfermedades infecciosas en los hospitales, lo que implica controlar las visitas a los pacientes y el ambiente en las instalaciones de emergencia

Estos conocimientos los han aplicado con todo rigor las autoridades de Corea del Sur en la pandemia actual, y de ahí el éxito que han tenido.

Después, se encontraron anticuerpos contra el MERS-CoV en camellos de muchos países, incluyendo las Islas Canarias (Gutiérrez et al., 2105), y se aislaron (y se aíslan) virus muy similares en numerosas especies de murciélagos y en zonas tan alejadas como Europa y Sudáfrica, donde se aisló un virus cuya secuencia solo se diferenciaba de la de MERS-CoV en un 0,3 \% de un murciélago insectívoro de la especie Neoromicia zuluensis (Geldenhuys et al., 2018).

Los datos actuales indican que los virus antecesores del MERS podrían haber estado en murciélagos insectívoros del Viejo Mundo (Europa, Asia y Áfri- 
ca) de la familia Vespertilionidae, a la que pertenecen los géneros Pipistrellus y Neomicia, desde hace cientos de años.

La pandemia actual por SARS-CoV-2 no es, por tanto, un fenómeno raro. Un informe muy reciente (29/10/2020) de la Plataforma Intergubernamental sobre Biodiversidad y Servicios de los Ecosistemas dice que estudios científicos señalan que puede haber hasta 850.000 virus animales con capacidad de infectaral hombre

El informe resalta que las mismas transformaciones ambientales que impulsan la pérdida de biodiversidad y el cambio climático, principalmente la deforestación, la expansión e intensificación agroganadera y el comercio y consumo de animales silvestres pueden hacer que las pandemias o grandes epidemias sean cada vez más frecuentes, como ha sucedido en los últimos años.

Hay un amplio consenso en que el SARS-CoV-2 actual tiene su origen en murciélagos y, aunque aún no está totalmente aclarado, todo apunta que el animal que acercó el virus original de los murciélagos al hombre es el pangolín (Manisjavanica), muy apreciado, aunque prohibido en la cocina oriental (Liu et al., 2020; Lam et al., 2020).

\section{Bibliografía}

Annan, A., Baldwin, H.J., Corman, V.M., Klose, S.M., Owusu, M., Nkrumah, E.E., Badu, E.K., Anti, P., Agbenyega, O., Meyer, et al. 2013. Human betacoronavirus 2c EMC/2012-related viruses in bats, Ghana and Europe. Emerging Infectious Diseases, 19:456-459

Boniotti, M.B., Papetti, A., Lavazza, A., Alborali, G., Sozzi, E., Chiapponi, C., Faccini, S., Bonilauri, P., Cordioli, P., y Marthaler, D. 2016. Porcine epidemic diarrhea virus and discovery of a recombinant swine enteric coronavirus, Italy. Emerging Infectious Diseases, 22:83-87

Carvajal A., Argüello H., Martínez-Lobo F. J., Costillas, S., Miranda, R., de Nova, P.J.G.y Rubio, P., 2015. Porcine epidemic diarrhoea: new insights into an old disease. Porcine Health Management, 1:12

Cho, S.Y., Kang, J.M., Ha, Y.E., Park, Lee J.Y, Ko, J.H., Lee, J.Y., Kim, J.M, Kang, C.I., Jo, I.J., Ryu, et al. 2016. MERS-CoV outbreak following a single patient exposure in an emergency room in South Korea: an epidemiological outbreak study. Lancet, 388:994-1001

Cui, J. Li, F. y Shi, Z.L., 2019. Origin and evolution of pathogenic coronaviruses. Nature Reviews Microbiology, 17:181-192

de Nova, P.J.G., Cortey, M., Díaz, I., Puente, H. Rubio, P., Martín, M. y Carvajal, A. 2020. A retrospective study of porcine epidemic diarrhoea virus (PEDV) reveals the presence of swine enteric coronavirus (SeCoV) since 1993 and the recent 
introduction of a recombinant PEDV-SeCoV in Spain. Transboundary and Emerging Diseases, 67:2911-2922

Fabricant, J., 1998. The early history of infectious bronchitis. Avian Diseases, 42:648650

Gao, H., Yao, H., Yang, S., Li, L. 2016. From SARS to MERS: evidence and speculation. Frontiers in Medicine, 10:377-382

Geldenhuys, M., Mortlock, M., Weyer, J., Bezuidt, O. Seamark, E.C.J., Kearney, T., Gleasner, C., Erkkila, T.H., Cui,H. y Markotter, W. 2018. A metagenomic viral discovery approach identifies potential zoonotic and novel mammalian viruses in Neoromicia bats within South Africa. PLoS One, 13:e0194527

Gutiérrez, C., Tejedor-Junco, M.T., González, M., Lattwein, E. y Renneker, E. 2015. Presence of antibodies but no evidence for circulation of MERS-CoV in dromedaries on the Canary Islands. EuroSurveillance, 20(37)

Hilgenfeld, R., Peiris, M., 2013. From SARS to MERS: 10 years of research on highly pathogenic human coronaviruses. Antiviral Research, 100:286-295

Huang, Y.W., Dickerman, A.W., Piñeyro, P., Li, L. Fang, L., Kiehne, R., Opriessnig, T. y Meng X.J. 2013. Origin, evolution, and genotyping of emergent porcine epidemic diarrhea virus strains in the United States. MBio, 4:eoo737-13

Jordan, B., 2017. Vaccination against infectious bronchitis virus: a continuous challenge. Veterinary Microbiology, 206:137-143

Knobler, S., Mahmoud A., Lemon, S., Mack, A., Sivitz, L. y Oberholtzer K. (Eds.) 2004. Forum on Microbial Threats. Learning from SARS: Preparing for the Next Disease Outbreak - Workshop Summary. National Academies Press. Washington DC, USA. ISBN: 0-309-59433-2

Lam, T.T., Jia, N., Zhang, Y.W., Shum, M.H....y Cao W.C. 2020. Identifying SARSCoV2-related coronaviruses in Malayan pangolins. Nature, 583:282-285

Laude, H., Rasschaert, D., Delmas, B., Godet, M., Gelfi, J. y Charley, B. 1990. Molecular biology of transmissible gastroenteritis virus. Veterinary Microbiology, 23:14754

Laude, H., Van Reeth, K., Pensaert, M., 1993. Porcine respiratory coronavirus: molecular features and virus-host interactions. Veterinary Research, 24:125-50

Li, G., Chen, Q., Harmon, K.M., Yoon, Schwartz, K.J., Hoogland,M.J., Gauger, P.C., Main,R.G. y Zhang, J. 2014. Full-Length genome sequence of porcine Deltacoronavirus strain USA/IA/2014/8734. Genome Announcements, 2:eoo278-14

Liu, P., Jiang, J.Z., Wan, X.F., Hua, Y., Li, L., Zhou, J., Wang, X., Hou, F., Chen, J., Zou, J., y Chen, J. 2020. Are pangolins the intermediate host of the 2019 novel coronavirus (SARS-CoV-2)? PLoS Pathogens, 16:e1008421

Marthaler, D., Jiang, Y., Collins, J., Rossow, K., 2014. Complete Genome Sequence of 
Strain SDCV/USA/Illinois121/2014, a Porcine Deltacoronavirus from the United States. Genome Announcements, 2:e00218-14

Ohd, H.A., Al-Tawfiq, J.A., Memish, Z.A., 2016. Middle East Respiratory Syndrome Coronavirus (MERS-CoV) origin and animal reservoir. Virology Journal, 13:87

Pedersen, N.C., Boyle, J.F., Floyd, K., 1981. Infection studies in kittens, using feline infectious peritonitis virus propagated in cell culture. American Journal of Veterinary Research, 42:363-367

Petrosillo, N., Viceconte, G., Ergonul, O., Ippolito, G. y Petersen, E. 2020. COVID-19, SARS and MERS: are they closely related? Clinical Microbiology and Infection, 26:729-734

Scheld, W. M., Hughes, J. M. y Whitley, R.J (Eds.). 2016. Emerging Infections 10. ASM Press, Washington DC., USA. ISBN 9781555819453 (eBook)

Shehata, M.M., Chu, D.K., Gomaa, M.R., AbiSaid, M. El Shesheny, R., Kandeil, A., Bagato, O., Chan, S.M.S., Barbour, E.K., Shaib, H.S., et al. 2016. Surveillance for Coronaviruses in Bats, Lebanon and Egypt, 2013-2015. Emerging Infectious Diseases, 22:148-150

Singh, S. K. (ed.), 2014. Viral infections and global change. Wiley Blackwell, Hoboken, New Jersey, USA. ISBN: 978-1-118-29787-2

Subudhi S, Rapin N, Misra V., 2019. Immune system modulation and viral persistence in bats: Understanding viral spillover. Viruses, 11:192

Wang, Y.W., Yue, H., Fang, W., Huang, Y.W., 2015. Complete genome sequence of porcine Deltacoronavirus strain CH/Sichuan/S27/2012 from Mainland China. Genome Announcements, 3:e00945-15

Wang, L.F., Shi, Z., Zhang, S., Field, H., Daszak, P. y Eaton, B.T. 2006. Review of bats and SARS. Emerging Infectious Diseases, 12:1834-1840

Ye, Z.W., Yuan, S., Yuen, K.S., Fung, S.Y., Chan, C.P. y Jin, D.Y. 2020. Zoonotic origins of human coronaviruses. International Journal of Biological Sciences, 16:1686-1697

Zhou, P., Fan, H., Lan, T., Yang, X.L....y Ma, J.Y. 2018. Fatal swine acute diarrhoea syndrome caused by an HKU2-related coronavirus of bat origin. Nature, $556: 255-258$ 